\title{
PARAMETRIC STUDY OF THE EFFECT OF CROSS-FRAMES AND LATERAL BRACINGS ON FREE VIBRATION RESPONSE OF HORIZONTALLY CURVED I-GIRDER BRIDGES
}

\author{
Mohamed Abdel-Basset Abdo \\ Civil Engineering Department, Faculty of Engineering, Assiut University, \\ Assiut, Egypt.
}

(Received November 22, 2007 Accepted February 27, 2008)

\begin{abstract}
This study is concerned with parametric study of the effect of cross frames and bottom lateral bracings on the free vibration response of steel Igirder bridges during the time of construction using finite element technique. The study includes an important factor of free vibration response which is the frequency. The first ten mode frequencies are studied for each model. Based on the numerical results, it is shown that increasing the cross frame stiffness has slight effect on the frequency of curved I-girder systems and does not necessary lead to an increase in system frequencies. However, it is recommended to use maximum slenderness ratio, $\lambda_{\max }=140$ since it gives optimum frequencies for curved I-girder systems for all degrees of curvature. Also, it is found that the suitable distance between cross frames in curved systems ranges from $5 \mathrm{~m}$ to $3 \mathrm{~m}$. On the other hand, an increase in flange width has a significant effect on normalized frequency and as the bottom flange increases the frequency is increased for all degrees of curvature. Moreover, it is found that the increase in number of girders or girder spacing has a negligible effect on the free vibration response of curved Igirder bridges of low degree of curvature. However, their effect on frequencies is more pronounced in girders of high degrees of curvature. The presence of lateral bottom bracings has great effect on the frequencies of lower modes. So, existence of lateral bracings of any type is so useful for free vibration response of curved systems during construction.
\end{abstract}

KEYWORDS: Parametric study, cross frames, lateral bracings, free vibration response, horizontally curved I-girder bridges.

\section{INTRODUCTION}

Horizontally curved bridges have become an important component in highway systems, especially in densely populated cities such as Cairo and Alexandria in Egypt. Indeed, horizontally curved bridges offer the following advantages over bridges built from a series of straight girder chords: 1) fewer substructure units (piers) are required, 2) less land space is needed, and 3) traffic design speeds can be maintained. Moreover, the shape of horizontally curved bridges is more aesthetically pleasing than the shape of similar chorded structures. Such bridges may be entirely constructed of reinforced concrete, pre-stressed concrete, or composite concrete deck on steel I- or box girders. 
Curved steel I-girder bridges are the preferred choice because of its simplicity of fabrication and construction, fast speed of erection, and excellent serviceability performance, [1].

In some structures such as balconies, highway bridges and interchanges in large urban area, I-girders curved in plan are frequently employed. These curved girders are subjected to large torsional loads. So, it is necessary to reinforce them to eliminate the torsional stresses and displacements. The reinforcement may be achieved using cross frames or cross frames in addition to lateral bracing system. Usually, a series of cross frames act together with the longitudinal beams or girders to form a system that behaves as a unit. On the other hand, using lateral bracings not only transmits the wind loads to substructure but also increases the torsional stiffness of the bridge since the behavior gravitates towards that of a multi-cell box section. Indeed, in straight right-angled bridges, cross frames and lateral bracings act as secondary members in maintaining structural integrity. However, in horizontally curved and skewed bridges, the interaction of bending and torsion causes these components to become major load-carrying elements (primary members), [2].

In general, there are few loads that are truly static in nature. Most loading that is of concern to the bridge designer is dynamic. Dynamic loads not only occur while the bridge is in-service, but also during construction where they can result from equipment impact loads, impact and cyclical loads that occur when the deck is being placed (e.g. placement and consolidation of the concrete), or accidental vibrational loads. These loadings can lead to locked-in stresses and changes in the geometry of the bridge prior to being placed into service which could alter its behavior from what is expected, [3]. Thus, alignment problems that may result from costly construction delays could be minimized.

Considerable research effort has been dedicated to studying the behavior of curved steel bridges. Some of the work has examined the affects of cross-frames on curved bridge response. Yoo and Littrell [4] have studied the effect of cross bracing on curved girders. They used shell elements to model the web of the steel beam. They derived an equation for the preliminary design of cross frame spacing for curved Igirder bridges. Unfortunately, they neglected a potential parameter such as the flange width. Davidson et al. [5] have also investigated the effect of cross frame spacing for curved I-girder composite bridges. They recommended using two equations for the preliminary design of cross frame spacing for curved I-girder bridges for noncomposite dead loads. However, they used beam elements (not shell elements) to model the flanges and they did not take the effect of cross frame stiffness into consideration. Also, Abdo and Abul-Wafa [6] recommended two equations for the preliminary design of cross frame spacing for curved I-girder bridges constructed with shoring taking into account the stiffness of cross frames.

Limited studies of lateral bracing systems in horizontally curved I-girder bridges have been performed. The effect of top and bottom lateral bracing on girder stress levels for single and continuous curved multi-girder bridge systems was studied by Schelling et al. [7]. They have used the equivalent truss system to simulate the girders where the flanges and web of the girders are replaced with equivalent truss members. With a system of girders modeled in this manner, the deformation of the web was not accounted. Multi-girder bridges were also examined to determine the effect that placement of a concrete deck slab had on girder response with top and bottom 
lateral bracing. Heins and Jin [8] examined live load distribution considering the effects of lateral bracing for single and continuous curved composite I-girder bridges using a three-dimensional space frame formulation. Influences of bottom lateral bracing on load redistribution were considered and girder design equations were presented for use in conjunction with grid solutions or preliminary designs. Hirasawa et al. [9] studied experimentally and analytically the effect of lateral bracings on small test specimen of a two girder bridge. They concluded that the lateral bracings enable the bridge to improve its torsional stiffness and that some arranging patterns of lateral bracings have great effects on displacements despite using a small number of them. ElMezaini et al. [10] investigated the effect of bottom wind bracings on the structural performance of a bridge subjected to Egyptian truck loading. The bridge model was a straight composite steel-concrete bridge. They concluded that wind bracings significantly increase both the flexural and torsional stiffness of such bridges when taken into account in design. Abdo [11] investigated the effect of bottom lateral bracings on the behavior of composite steel-concrete bridges curved in plan. Indeed, existence of lateral bracings resulted in significant reduction of both bending and warping stresses as well as vertical and radial displacements. Huang and Wang, [12] studied the dynamic behavior of horizontally curved I-girder bridges. They recommended further research on the effect of bottom lateral bracings on the dynamic analysis of I-girder bridges. Maneetes and Linzell [3] investigated the free vibration response of an experimental, single span, non-composite, curved I-girder bridge during construction with varying cross-frame member cross-sections, geometries, and spacings. Also, they studied the effects of lateral bracings on response. Unfortunately, they used beam elements to model girder flanges and stiffeners of interior girders and they used the results of the first mode only. Also, they did not take the effect of some factors into consideration such as: $\mathrm{L} / \mathrm{R}$ ratio, number of girders, flange width, and different patterns of lateral bracings.

As the aforementioned summary indicates, there have been limited studies of the effects of cross-frames and bracing members and their orientation in plan on the dynamic response of curved bridges. So, the objective of this paper is to investigate the influence of different major parameters of cross frames and bottom lateral bracings on the free vibration response of horizontally curved non-composite girders during construction. Indeed, understanding how curved steel bridges respond to free vibration during construction can help reduce stresses and displacements. A careful numerical study is carried out by using the finite element method to analyze the behavior of Igirder bridges curved in plan. Both steel webs and flanges of beams are modeled using shell elements. Cross frames and/or bracing members are modeled using beam elements. The convergence of frequencies is obtained via comparing the results of different meshes.

\section{THEORETICAL BACKGROUND}

\subsection{Stress Distribution In Curved Beams [6]}

It is well known that horizontally curved I-girders undergo a coupled lateral-bending moment of the top and bottom flanges due to curvature, termed the torsional warping moment or "bimoment" which induces warping of the girder cross section as shown in 
Fig. 1. For curved I-girder bridge system under gravity loading where the rotation of the cross section is restrained by connecting cross frames or diaphragms, the bimoment and thus lateral bending of the flanges, varies dramatically in magnitude and direction along the span with lateral moment peaks generally occurring at the cross-frame locations. At the cross frame locations, the bimoment increases the normal stresses on the outside of curvature edge and decreases stress on the inside. In the intervals between cross frames, the direction of the bimoment is reversed and the highest stresses occur on the inside edge of the flanges. The individual and combined normal stress distribution in the flanges due to major axis bending and bimoment are shown in Fig. 2.
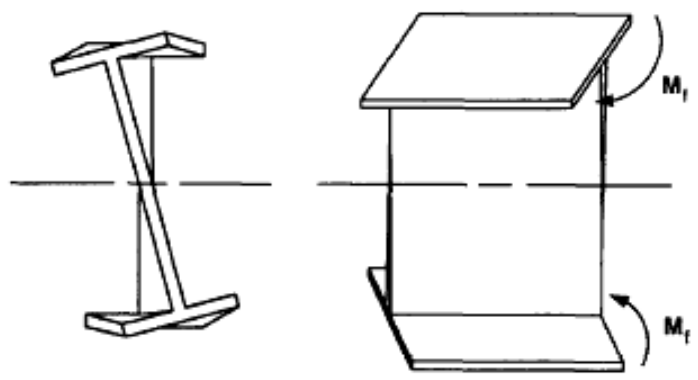

Figure 1: Warping of cross section.

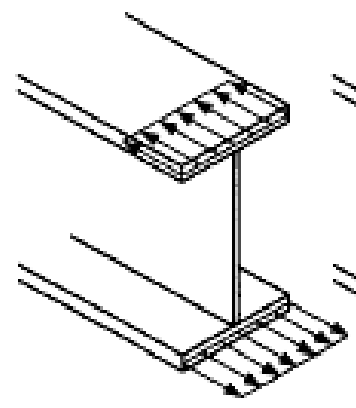

(a)

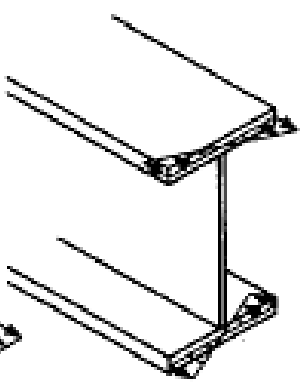

(b)

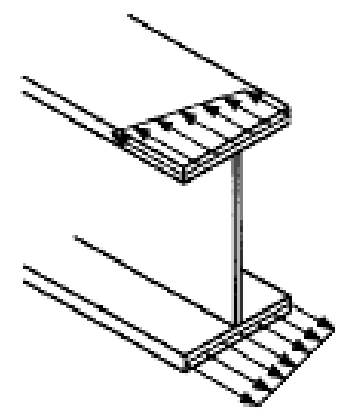

(c)

Figure 2: Normal stress distribution in curved l-girder flanges: (a) major axis bending stress; (b) warping stress; (c) combined bending and warping stress

\subsection{Bending And Warping Stresses}

For simplicity, consider the following approach based on the behavior of a single horizontally curved beam. Under gravity loads and with the area of the flanges much larger than that of the web, the tangential force $P$ in the flanges due to vertical moments can be approximated by

$$
P=\sigma_{b} b_{f} t_{f}=M_{v} / d,
$$

where $P=$ normal stress resultant in the flange due to vertical moment; $M_{v}=$ vertical (major axis) bending moment; $d=$ girder depth; $\sigma_{b}=$ normal stress in flange due to vertical bending; $b_{f}=$ flange width; and $t_{f}=$ flange thickness. 
If the flange is curved with a radius $R$, radial components $F_{r}$ of the internal forces $P$ are developed designated as flange distributed load $q$. The magnitude of $q$ is obtained from the equilibrium condition of a very small segment of the girder. It is important to mention that $q$ and $P$ vary along the girder length, but for a very small segment they may be considered constant, [5]. Equilibrium requires:

$$
q=P / R
$$

and the lateral bending or warping stress can be expressed as

$$
\sigma_{w}=M_{f} / S_{f},
$$

where $M_{f}=$ lateral-flange bending moment due to the bimoment; and $S_{f}=$ section modulus of the flange in the horizontal plane. The lateral-section modulus for rectangular flange can be expressed as:

$$
S_{f}=t_{f} b_{f}^{2} / 6 .
$$

If we consider the flange as a continuous beam with rigid supports (cross frames) at a spacing of $l$, the lateral flange bending moment due to virtual load $q$ can be conservatively approximated by

$$
M_{f}=q l^{2} / 10, \quad \text { or } \quad M_{f}=q l^{2} / 12,
$$

The relationship between cross-frame spacing $l$ and warping-to-bending stress ratio, $\sigma_{w b}$ can be easily derived. Indeed, warping-to-bending stress ratio $\sigma_{w b}$, is an important issue in preliminary design purposes so that the American Association of State Highway and Transportation Officials (AASHTO) [13] mandates the $\sigma_{w b}$ to be $\leq$ 0.50 . Indeed, the fundamental frequency of a bridge is proportional to the bridge stiffness.

\section{FINITE ELEMENT ANALYSIS}

\subsection{Bridge Geometry}

The bridge model used in this analysis is one of the existing and newly designed bridges in Egypt [1]. The basic model of the bridge consists of four steel girders, $2 \mathrm{~m}$ spacing between web lines, and length of the bridge is $24 \mathrm{~m}$. Webs of the girders are $130 \times 1.3 \mathrm{~cm}$ and top and bottom flanges are $40 \times 4 \mathrm{~cm}$. The steel beams are connected with cross frames of $1 \mathrm{~L} 70 \times 70 \times 7$ spaced at intervals of $4 \mathrm{~m}$ for both straight and curved systems. Indeed, Maneetes and Linzell [3] have found that both K-type and Xtype cross frames give nearly identical results. So, only bridges having $\mathrm{X}$-shaped cross diaphragms are considered in the current work. A cross section of the finite element model representing the basic section of the bridge is shown in Fig. 3(a). The material properties are: (a) steel: density, $\rho=7850 \mathrm{~kg} / \mathrm{m}^{3}$; yield stress, $\sigma_{y}=360 \mathrm{MPa}$; Young's modulus, $E=210 \mathrm{GPa}$; Poisson's ratio, $v=0.3$ and (b) concrete: density, $\rho=2500$ $\mathrm{kg} / \mathrm{m}^{3}$; compressive strength, $30 \mathrm{MPa}$; Young's modulus, $E=25 \mathrm{GPa}$, Poisson's ratio, $v=0.2$. 


\subsection{Model Description}

The finite-element modeling in the present study was carried out using the MARC/Mentat package [14], [15]. A three-dimensional finite element model with the following characteristics had been used: (1) a four-node thick shell element with six degrees of freedom at each node (element 75) was used to model steel webs and steel flanges; (2) a two-node beam element with six degrees of freedom at each node (element 52) was used to model both cross frames and bracing members (if any). For curved beams, all geometry and boundary conditions were modeled in the cylindrical coordinate system. One of the supports of the system is hinged (free to rotate about the radial direction) and the other is roller (free to rotate around the radial direction and to translate in the tangential direction).

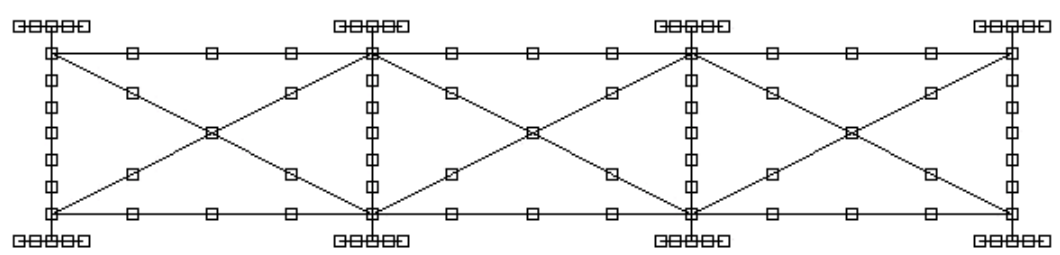

(a)

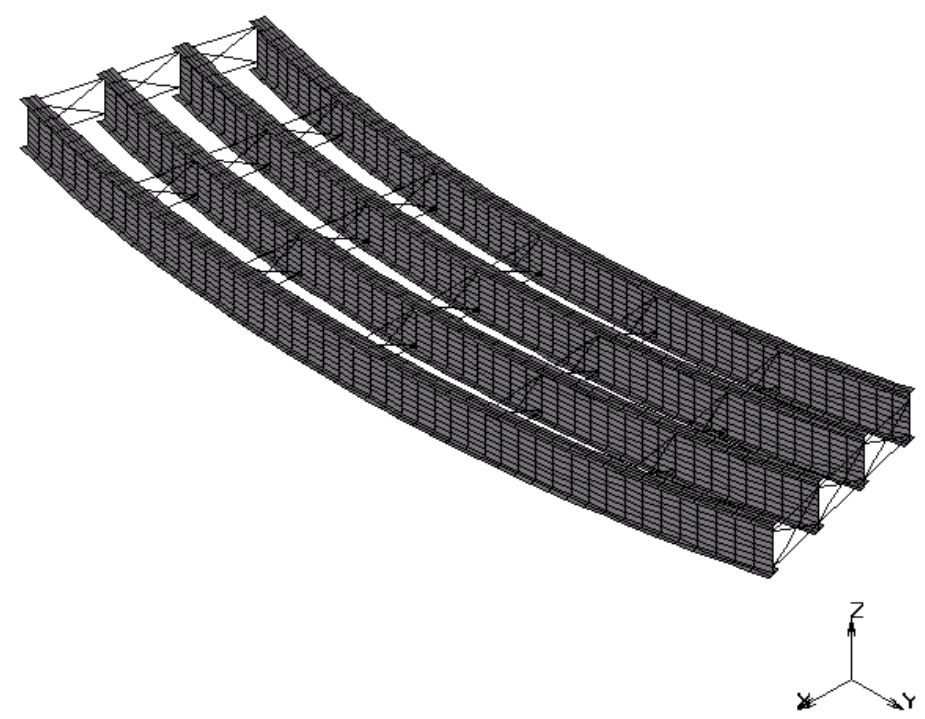

(b)

Figure 3: Bridge model: (a) finite element representation of bridge cross section; (b) isometric view of the bridge

Three different meshes are investigated and the fundamental frequencies are convergent for finer mesh. An isometric view of the finite element model of the basic section is shown in Fig. 3(b), with 3408 nodes and 3563 elements (8 elements for web and 4 elements for each flange and 48 shell elements along the span). The height of cross frames is 6 shell elements of the web height and each member is divided into 4 
elements. In present study, the following assumptions are considered: (1) the bridges are simply-supported; (2) the bridges have constant radii of curvature and uniform cross sectional area between support lines; (3) only own weight of steel beams, cross frames, and lateral bracings are considered; (4) all materials are elastic and homogenous; (5) webs of the steel girders are vertical, and (6) deformations are assumed to remain within the limits of small displacement theory.

\section{PARAMETRIC STUDY}

The present investigation considers the effect of a number of design variables on the free vibration response of simply-supported curved girder systems including stiffness of cross frames, space between cross frames, degree of curvature, flange width, number of girders, girder spacing in addition to different types of bottom lateral bracings. An analytical approach using three dimensional finite element models is used for the present investigation to isolate which parameters are significant in the design sense for structural frequencies.

A large number of finite element models were constructed, and normalizing techniques were used to help generalize the results. For the sake of comparison study, the length of the outside girder of the curved system is taken the same as that of the straight system $(24 \mathrm{~m})$ and the addition of other girders is on the inside of curvature to preserve a constant length and radius of curvature for the outside girder. When investigating the influence of one parameter on the behavior of composite system, other parameters are kept constant. Curved bridges with span-to-radius of curvature ratios $L / R$ considered are $0.1,0.3$, and 0.5 , i.e., the radii of curvatures are 240,80 and $48 \mathrm{~m}$, respectively. Since both of the vertical and lateral bending stresses as well as displacements are small under the effect of own weight, only the frequencies of the models are taken into account. For all models, the first ten natural frequencies of the system are calculated with the physical and mechanical properties mentioned above.

\section{RESULTS AND DISCUSSIONS}

The following description summarizes the effects that the parameters mentioned previously have on curved I-girder systems.

\subsection{Stiffness Of Cross Frames And L/R Ratio}

According to Egyptian Code of Practice (ECP) for steel construction and bridges [16], the maximum slenderness ratio $\left(\lambda_{\max }\right)$ for roadway bridge members, roadway bridge bracings and building bracings in compression should not exceed 110, 140, and 200, respectively. So, when investigating the effect of stiffness of cross frames on the behavior of a curved I-girder system, the three different slenderness ratios are considered in this study. Also, three span-to-radius of curvature ratios, $L / R=0.1,0.3$, and 0.5 in addition to straight girder with $L / R=0.0$ are studied. The percentage change in frequency is calculated as follows:

$$
\text { percentage change in frequenc } y=\left(\frac{f_{c}-f_{s}}{f_{s}}\right) \times 100 \text {, }
$$


where $f_{c}$ and $f_{s}$ are the frequencies [Hz] of curved and straight systems, respectively.

Figure 4 shows the percentage change in fundamental frequencies of curved bridge systems for different $\mathrm{L} / \mathrm{R}$ ratios for three different slenderness ratios of cross frames. It is shown that the percentage changes in frequencies for curved systems are greater than zero which means that curved systems have greater frequencies than the straight one. This can be interpreted by the fact that lengths of the outside girders of curved systems have the same length as that of the straight one but other girders of curved systems have smaller lengths than those in straight system. Also, it is shown that the percentage changes of frequency for high degree of curvatures are higher than those of low degree of curvature. This is due to the fact that the curved system of high degree of curvature has large subtended angle and consequently their interior girders have smaller lengths than those of low degree of curvature. Moreover, it can be seen that the fundamental frequency of a simple-span curved system with low degree of curvature is approximately equal to that of the straight one on condition that the span of straight bridge and the outer span of the curved one is equal. It is of interest to mention that the first mode is a symmetrical lateral mode for all studied models.

In Fig. 4 it is seen that the maximum change in frequency occurs with slenderness ratio $\left(\lambda_{\max }=140\right)$. Also, an increase of the cross frame stiffness or reducing the slenderness ratio from $\lambda_{\max }=200$ to $\lambda_{\max }=140$ leads to an increase in fundamental frequencies for all degrees of curvature. However, an increase of the cross frame stiffness from $\lambda_{\max }=140$ to $\lambda_{\max }=110$ leads to a decrease in frequencies for all degrees of curvature. This is interpreted by the fact that an increase in the cross frame stiffness increases the stiffness of the I-girder system but further increase in cross frame stiffness leads to an increase in mass and consequently leads to a decrease in frequency. So, it can be inferred that increasing the cross frame stiffness does not necessary lead to an increase in system frequencies and slenderness ratio, $\lambda_{\max }=140$ gives the optimum frequencies for curved I-girder systems of all degrees of curvature.

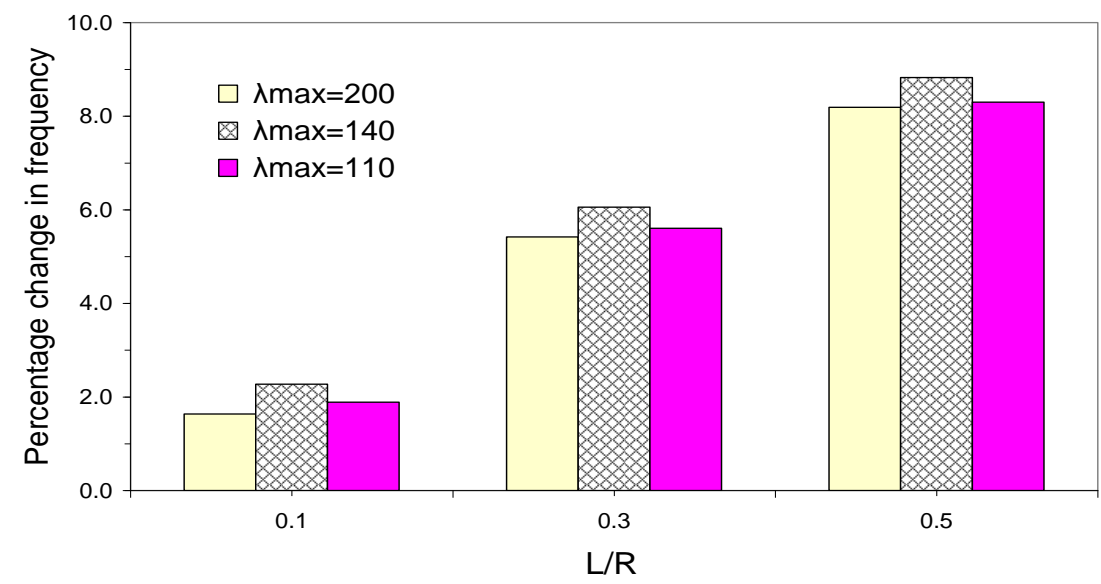

Figure 4: Effect of cross frame slenderness ratio on fundamental frequency. 


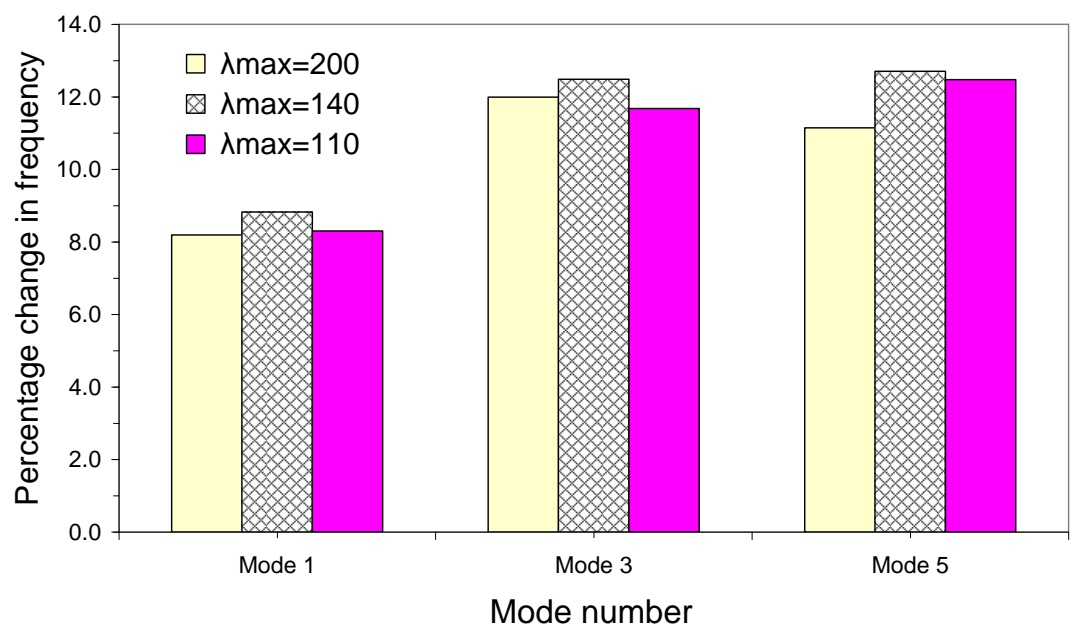

Figure 5: Effect of cross frame slenderness ratio on frequencies for different modes, $(\mathrm{L} / \mathrm{R}=0.5)$.

To show the effect of cross frame slenderness ratios on frequencies of curved I-girder systems, the relationship between percentage change in frequency and mode number for $L / R=0.5$ for different cross frame slenderness ratios are plotted in Fig. 5. It is shown that the maximum change in frequency occurs with slenderness ratio $\left(\lambda_{\max }=\right.$ 140). Also, an increase of the cross frame stiffness or reducing the slenderness ratio from $\lambda_{\max }=200$ to $\lambda_{\max }=140$ leads to an increase in frequencies for all modes and the percentage of increase in frequencies differs from one mode to the other. However, further increase of the cross frame stiffness from $\lambda_{\max }=140$ to $\lambda_{\max }=110$ leads to a decrease in frequencies for all modes. It is of interest to mention that the maximum increase in frequency is found in mode five and is just $1.55 \%$. So, the stiffness of cross frames has slight effect on the curved I girder systems. For the sake of comparison, the cross frames with $\lambda_{\max }=140$ is used in investigating the effect of other parameters on the behavior of curved steel girders. It is of interest to mention that the third mode is an anti-symmetrical lateral mode and the fifth mode is a lateral-torsional mode for all studied models.

\subsection{Cross Frame Intervals}

To determine the effect of space between cross frames on frequencies of a curved bridge system, models were created with varying cross frame intervals and curvatures. The space between cross frames $=L / N$ where, $L$ is the length of the outside girder and $N$ is the number of intervals of cross frames. The relationship between the number of cross frame intervals and the normalized frequencies for all degrees of curvatures is illustrated in Fig. 6. Herein, the frequencies of the curved systems with four intervals are assumed as reference values for normalization (the space between cross frames is 6 $\mathrm{m})$. So, the value of 1.0 would represent a curved system with the same response as that with four intervals and of the same L/R ratio.

In Fig. 6, it is shown that the number of cross frame intervals has a noticeable effect on normalized frequency. It is clearly shown that as the number of intervals 
increases the frequency is increased for all degrees of curvature. The effect of cross frame intervals on normalized frequency is almost the same for all degrees of curvature. Indeed, the increase in frequency is relatively high when the intervals increase from 4 to 6 (the space between cross frames is decreased from $6 \mathrm{~m}$ to $4 \mathrm{~m}$ ). Also, the frequency increases slightly when the intervals increase from 6 to 8 (the space between cross frames is decreased from $4 \mathrm{~m}$ to $3 \mathrm{~m}$ ). However, further increase of intervals from 8 to 12 (the space between cross frames is less than $3 \mathrm{~m}$ ) results in very small increase in frequency. So, it can be derived that the suitable distance between cross frames in curved systems ranges from $5 \mathrm{~m}$ to $3 \mathrm{~m}$ and further decrease of this distance is not so useful on the free vibration response of curved I-girder systems.

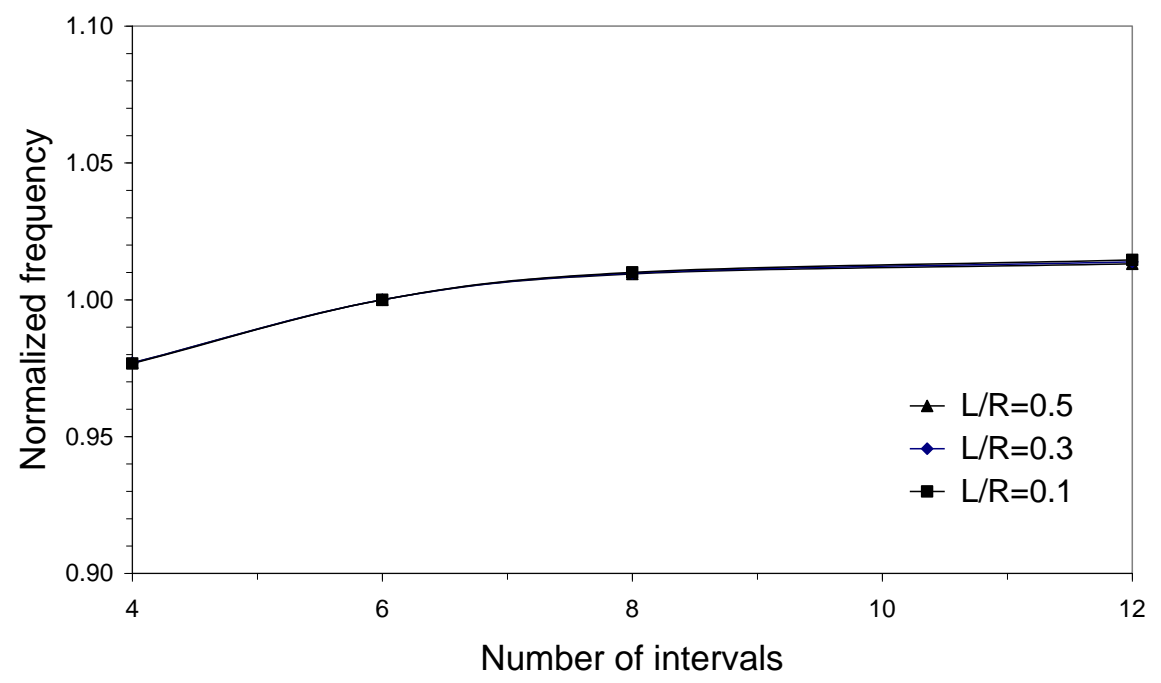

Figure 6: Effect of number of intervals of cross frames on normalized frequency.

\subsection{Flange Width}

To determine the effect of flange width on frequencies of a curved system, models were created with varying bottom flange widths and curvatures. Indeed, the width of bottom flange only is considered in the study because the floor which may be of reinforced concrete slab resting on top flange of steel girders or reinforced concrete slab which acts as a composite section with steel beams, and both of them constitute a wide top flange for the bridge system. The relationship between the width of bottom flange and the normalized frequency for three degrees of curvatures is plotted in Fig. 7. The bottom flange is considered 40, 50, and $60 \mathrm{~cm}$. Herein, the frequencies of the curved systems with bottom flange width $=40 \mathrm{~cm}$ are assumed as reference values for normalization. So, the value of 1.0 would represent a curved system with the same response as that with basic section and of the same $\mathrm{L} / \mathrm{R}$ ratio.

The increase in flange width has a significant effect on normalized frequency. It is clearly shown that as the bottom flange increases the frequency is increased for all degrees of curvature. The effect of flange width on normalized frequency is almost the same for all degrees of curvature. Indeed, the increase in flange width leads to a 
decrease in both bending and warping stresses. While bending stress is inversely proportional to flange width, warping stress is inversely proportional to the square of the flange width as shown in Eqs. (3) and (4). So, both bending and torsional stifnesses are increased greatly and as a result, a higher increase in frequency is obtained. The fundamental frequencies of curved systems are increased by $20 \%$ as the flange width increases from $40 \mathrm{~cm}$ to $50 \mathrm{~cm}$. Similar results are obtained for other modes. So, flange width has a significant effect on frequencies of curved I-girder systems. It is of interest to mention that the frequencies of straight systems are increased in a similar manner to that of curved systems as a result of increasing the flange width.

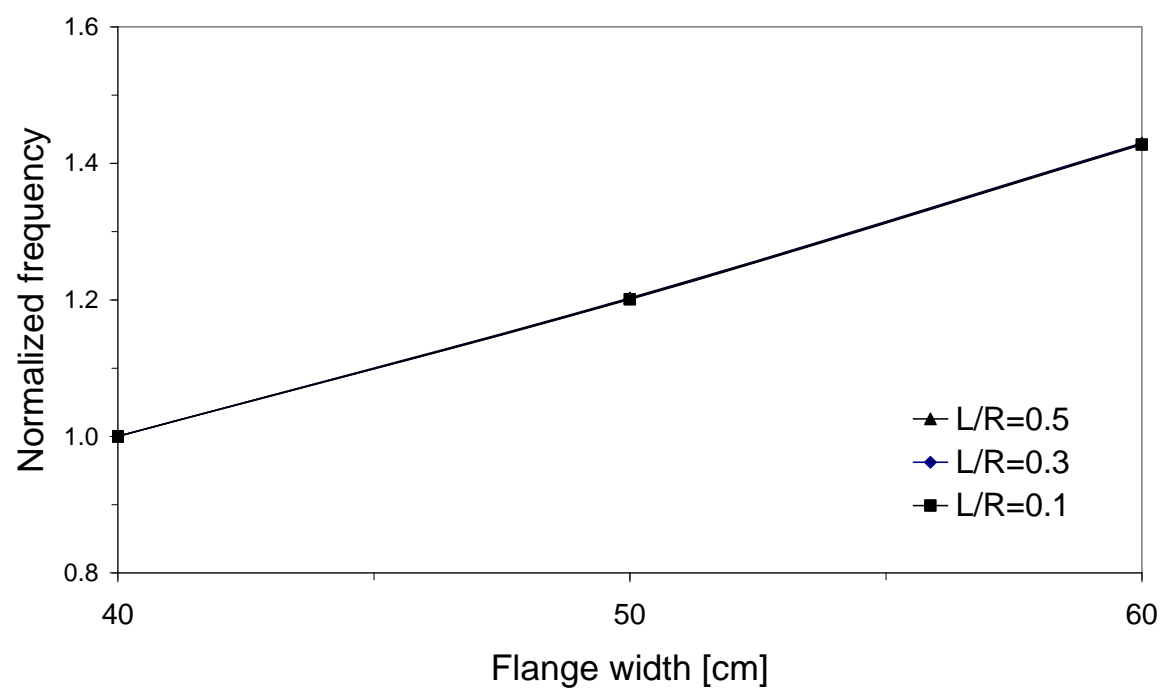

Figure 7: Effect of flange width on normalized frequency.

\subsection{Number of Girders and Girder Spacing}

To determine the effect that the number of girders in a curved system has on free vibration response, a series of models were developed with 4,5 , and 6 girders with varying curvatures. The models were created by keeping the spacing between girders constant and adding girders on the inside of curvature, thereby increasing the width of the system but preserving a constant length and radius of curvature for the outside girder. Herein, the frequencies of the curved systems with four girders are assumed as reference values for normalization. So, the value of 1.0 would represent a curved system with the same response as that with basic section and of the same L/R ratio.

For systems with low degree of curvature, the effect is found to be negligible on normalized frequency. However, as curvature increases, the addition of girders noticeably increases the fundamental frequency as demonstrated in Fig. 8. For L/R $=0.5$, the increase in frequency is nearly $5 \%$ when adding additional one bay and $10 \%$ when adding two bays. Indeed, the increase in frequency is due to the fact that as the number of girders is increased, the width of the system and therefore the lateral and torsional stiffness of the system as a whole are increased. Similar results are obtained 
for other modes of the curved system. Also, it is expected that a decrease in number of girders leads to a decrease in frequencies of curved systems.

To determine the effect that girder spacing has on the behavior of a curved system, the spacing between adjacent girders was varied from $2[\mathrm{~m}]$ to $2.5[\mathrm{~m}]$ and 3.0 $[\mathrm{m}]$ with the same cross section for different curvatures. The maximum slenderness ratio of cross frames is kept to be 140 . The frequencies of the curved systems with girder spacing $=2.0[\mathrm{~m}]$ are assumed as reference values for normalization. So, the value of 1.0 would represent a curved system with the same response as that with basic section and of the same L/R ratio. The relationship between girder spacing and normalized frequency are illustrated in Fig. 9 for the same cross section dimensions. The increase in girder spacing has a negligible effect on low degree of curvature. However, the effect of girder spacing on frequencies is more pronounced for high degrees of curvature and as girder spacing increases the fundamental frequencies are increased and similar results are obtained for other higher modes.

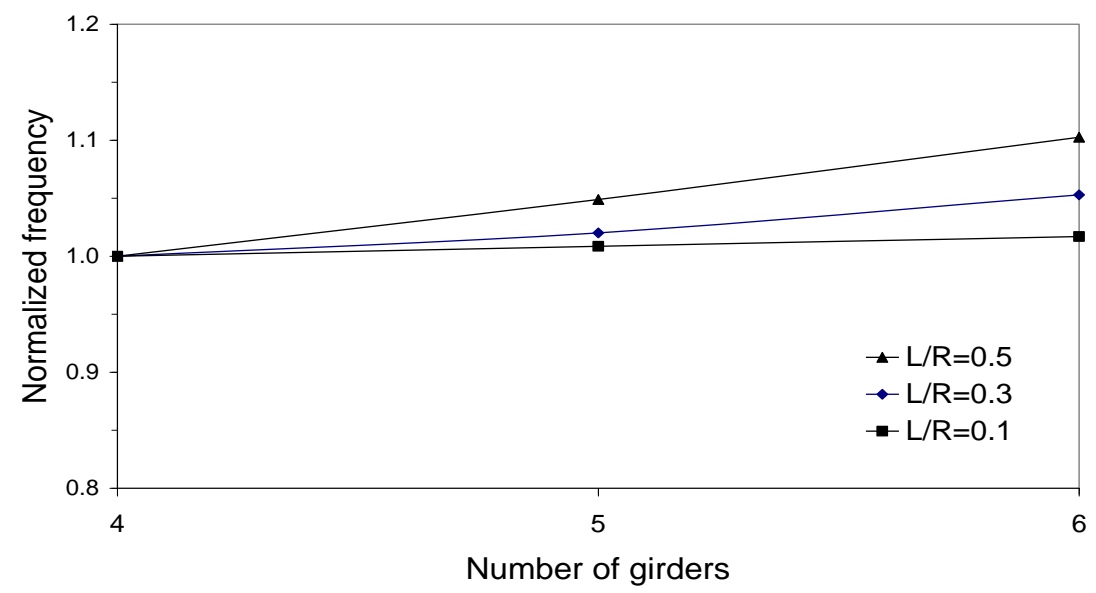

Figure 8: Effect of number of girders on normalized frequency.

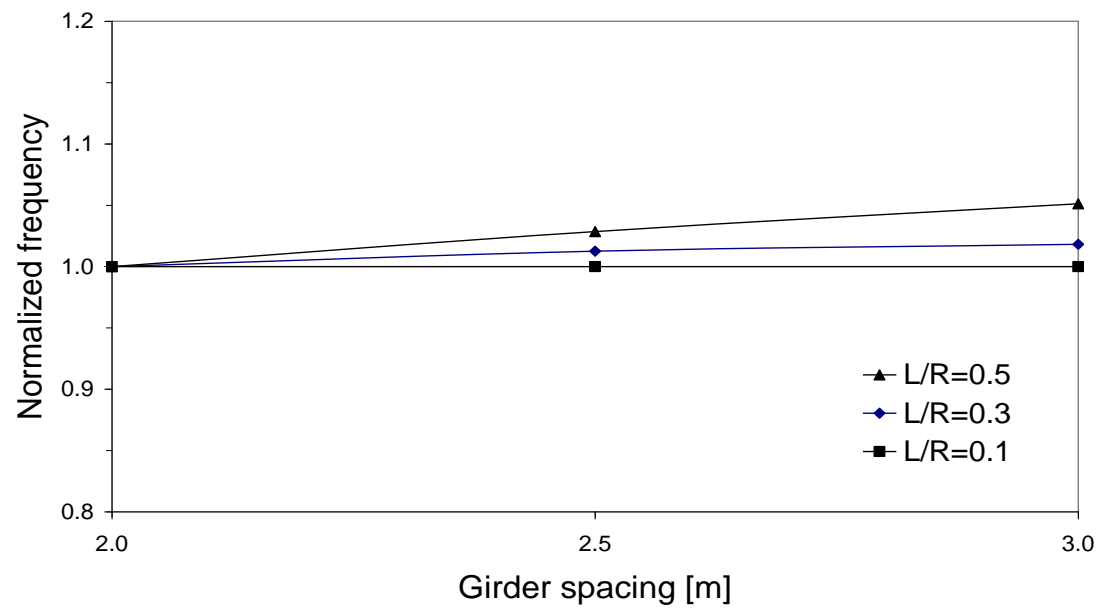

Figure 9: Effect of girder spacing on normalized frequency. 


\subsection{Bottom Lateral Bracings}

The present study considers the effect of different arrangement patterns of bottom lateral bracings on free vibration response of horizontally curved I-girder bridge. Figure $\mathbf{1 0}$ shows the six different bridge bracing configurations which are investigated in this study, namely: i) single-diagonal bracings in all bays in one direction (Type 1-a); ii) single-diagonal bracings in all bays in reverse direction (Type 1-b); (iii) X-bracings in all bays (Type 2); (iv) X-bracings in outer bays only (Type 3); (v) X- bracings in end and middle panels (Type 4); (vi) X-bracings in end panels only (Type 5). The cross section of lateral bracings are considered 1L $120 \times 120 \times 12$ for X-type bracings and $1 \mathrm{~L}$ $160 \times 160 \times 15$ for single diagonal bracings so as to keep the maximum slenderness ratio to be 140. It is important to mention that the cross sectional area of single diagonal bracings is nearly twice that of the $\mathrm{X}$-type bracings.

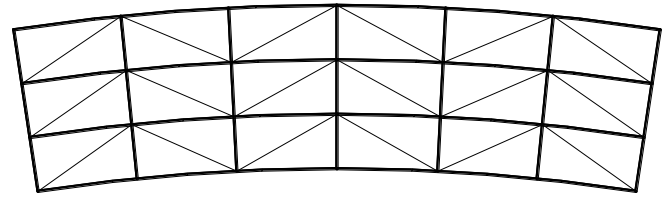

(a) Type 1-a

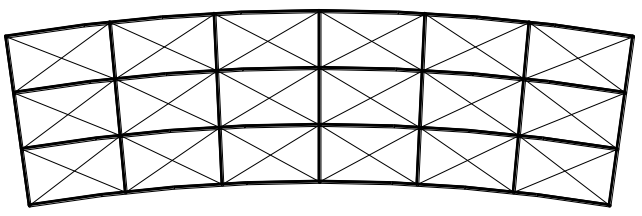

(c) Type 2

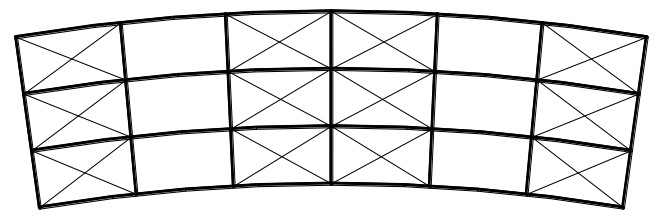

(e) Type 4

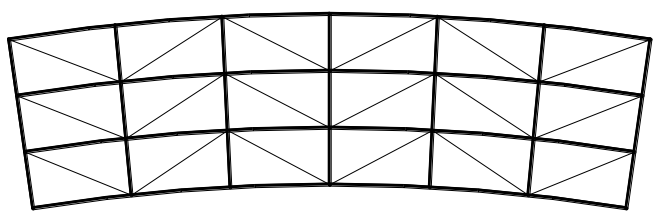

(b) Type 1-b

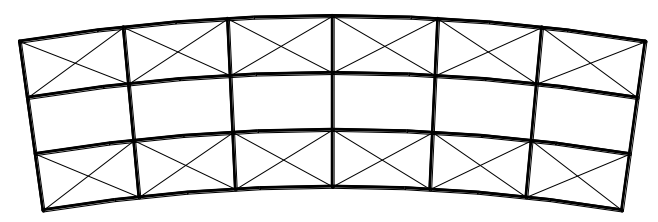

(d) Type 3

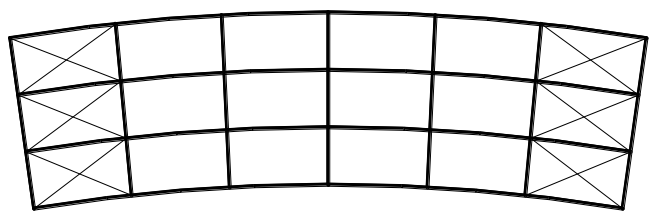

(f) Type 5

Figure 10: Arrangement patterns of bridge lateral bottom bracings: (a), (b) single diagonal bracings in all bays; (c) X-bracings in all bays; (d) X-bracings in outer bays; (e) X-bracings in end and middle panels; (f) X-bracings in end panels only.

Figure 11 shows the effect of bottom lateral bracings on normalized frequency of curved I-girder bridges for different span-to-radius of curvature ratios. The values obtained for curved systems are normalized to that with no lateral bracings and with the same length and cross section dimensions. So, the value of 1.0 would represent a curved system with the same response as that with basic section and of the same L/R ratio. From Fig. 11, it is clear that the existence of bottom lateral bracings has a great influence on the fundamental frequencies of the curved systems for all arrangement 
patterns (Type 1 to Type 5). Also, both of Type 1-a, and Type 1-b which consist of single diagonal in all bays have almost the same effect. Furthermore, it is shown that Type 2 which consists of X-bracings in all bays has the greatest frequency. Indeed, the frequency of the braced systems may exceed three times of that obtained using cross frames only. Also, it is shown that Type 3 at which the system is reinforced longitudinally with $\mathrm{X}$-bracings in outer bays only gives higher frequency than that of Type 4 which consists of the same number of bracing members but with different pattern. However, Type 5 which consists of X-bracings in end panels only gives the smallest increase in frequency of the studied reinforcement patterns. It is important to mention that for Type 5 of lateral bracings, the normalized frequency is almost the same for all radii of curvatures. Similar results are obtained for high order modes.

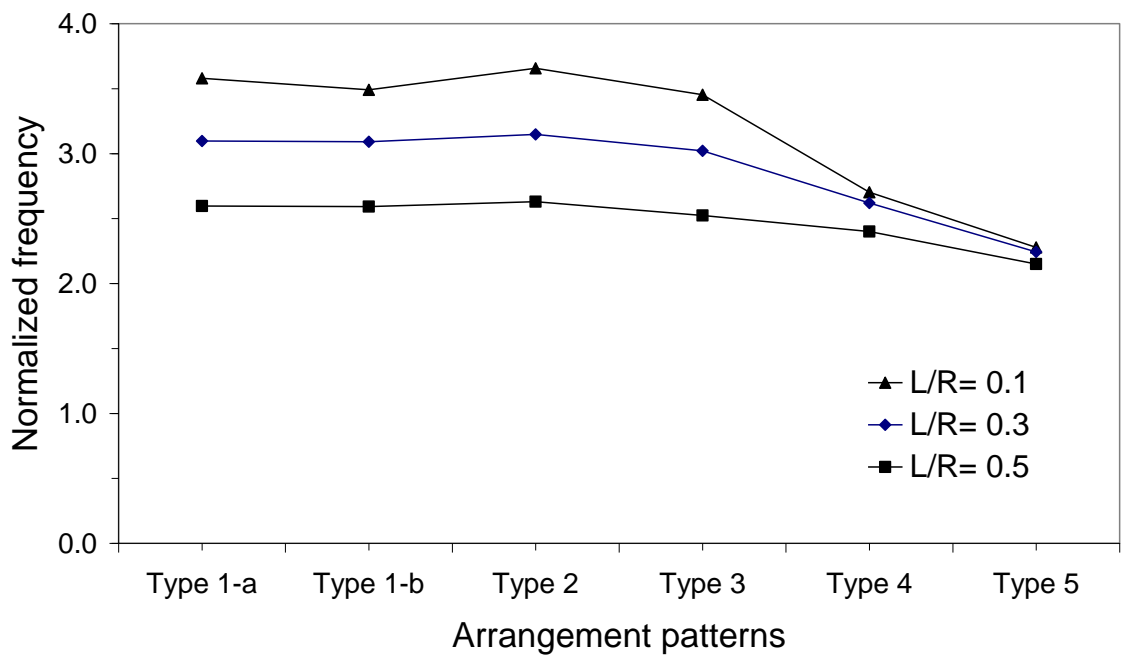

Figure 11: Effect of bottom lateral bracings on normalized frequency.

Lateral bracings in curved systems increase the frequency significantly unlike using cross frames only which has slight effect on frequency. This is due to the fact that the existence of lateral bracings near bottom flanges forms quasi-closed boxgirders and consequently increases both flexural and torsional stiffnesses of curved Igirders. On the other hand, it is shown that lateral bracings are more effective for straight girders and curved girders with low degree of curvature. It is found that the normalized frequency is 3.91 for straight girders but it is just 2.63 for $\mathrm{L} / \mathrm{R}=0.5$. This is due to the fact that for high degree of curvatures additional warping stresses are increased in addition to bending stresses. Indeed, from Fig. 11, it is shown that Type 2 is the most effective pattern of lateral bracings, especially for low degrees of curvature. On the other hand, though Type 1 (single diagonal system of bracings) gives high increase in frequency, the cross sectional area of members is nearly twice that of the $\mathrm{X}$ type bracings to satisfy the maximum slenderness ratio of bracings to be 140 . So, using single diagonal bracing pattern does not save a lot of materials than the X-bracings pattern. Also, Type 3 which consists of X-type bracings in outer bays only is preferable to Type 4 of the same bracing numbers. Though Type 5 which consists of X-bracings in end panels only gives the smallest increase in frequency of the studied reinforcement 
patterns, it still gives high frequency (more than two times of the frequency obtained using cross frames only). So, existence of lateral bracings of any type is so useful for free vibration response of curved systems.

\section{CONCLUSIONS}

Finite element modeling of structural steel I-girder beams curved in plan is presented in this paper. A parametric study of the effect of cross frames and bottom lateral bracings on the free vibration response of steel I-girder bridges during the time of construction is studied. Both steel webs and flanges of beams are modeled using shell elements. Cross frames and/or bracing members are modeled using beam elements. The convergence of frequencies is obtained via comparing the results of different meshes. The study includes an important factor of free vibration response which is the frequency. The first ten mode frequencies are studied for each model.

Based on the above results, it can be concluded that increasing the cross frame stiffness has slight effect on the frequency of curved I-girder systems and does not necessary lead to an increase in system frequencies. However, it is recommended to use maximum slenderness ratio, $\lambda_{\max }=140$ since it gives the optimum frequencies for curved I-girder systems for all degrees of curvature. Also, it is found that the suitable distance between cross frames in curved systems ranges from $5 \mathrm{~m}$ to $3 \mathrm{~m}$ and further decrease of this distance is not so useful on the free vibration response of curved Igirder systems. On the other hand, an increase in flange width has a significant effect on normalized frequency and as the bottom flange increases the frequency is increased for all degrees of curvature. An increase in flange width from $40 \mathrm{~cm}$ to $60 \mathrm{~cm}$ leads to an increase in fundamental frequency of $43 \%$ than that of the basic section. Moreover, it is found that the increase in number of girders or girder spacing has a negligible effect on the free vibration response of curved I-girder bridges of low degree of curvature. However, their effect on frequencies is more pronounced in girders of high degrees of curvature. As the number of girders or girder spacing increases the fundamental frequencies are slightly increased and similar results are obtained for other modes.

The presence of lateral bottom bracings has great effect on the frequencies of lower modes. The existence of lateral bracings may increase the fundamental frequency to more than three times of that obtained using cross frames only. Lateral bracings are more effective for straight girders and curved girders with low degree of curvature. Indeed, Type 2 of lateral bracings which consists of X-bracings in all bays has the greatest frequency of all of the studied reinforcement patterns. Though Type 5 which consists of X-bracings in end panels only gives the smallest increase in frequency of the studied patterns, it still gives high frequency (more than two times of the frequency obtained using cross frames only). So, existence of lateral bracings of any type is so useful for free vibration response of curved systems during construction.

\section{REFERENCES}

[1] Nasr, A. M., Amer A. H., Saleh M. M. and AbuHamd M. H.: "SIMPLIFIED LOAD DISTRIBUTION FACTORS FOR CURVED STEEL I-GIRDER BRIDGES BASED ON ECP 
LIVE LOADS", Eleventh International Colloquium on Structural and Geotechnical Engineering, $11^{\text {th }}$ ICSGE, Cairo, Egypt, 17-19 May (2005).

[2] Xanthakos, P. P.: "THEORY AND DESIGN OF BRIDGES", John Wiley and Sons, Inc., Chapter 12, 1443 pp., (1994).

[3] Maneetes, H. and Linzell, D.G.: "CROSS-FRAME AND LATERAL BRACING INFLUENCE ON CURVED STEEL BRIDGE FREE VIBRATION RESPONSE", $J$. Constructional Steel Research, Vol. 59, pp. 1101-1117, (2003).

[4] Yoo, C. H., and Littrell, P. C.: "CROSS-BRACING EFFECTS IN CURVED STRINGER BRIDGES”, J. Structural Engineering, ASCE, 112(9), pp. 2127-2140, (1986).

[5] Davidson, J.S., Keller, M.A., and Yoo, C.H.: "CROSS-FRAME SPACING AND PARAMETRIC EFFECTS IN HORIZONTALLY CURVED I-GIRDER BRIDGES”, $J$. Structural Engineering, ASCE, 122(9), pp. 1089-1096, (1996).

[6] Abdo, M. A.-B. and Abo El-Wafa, W.: "PARAMETRIC STUDY OF THE EFFECT OF CROSS-FRAMES ON THE BEHAVIOR OF COMPOSITE STEEL-CONCRETE GIRDERS CURVED IN PLAN AND CONSTRUCTED WITH SHORING", J. Engineering Sciences, Faculty of Engineering, University of Assiut, 34(5), (2006).

[7] Schelling, D., Namini, A. H., and Fu, C. C.: "CONSTRUCTION EFFECTS ON BRACING ON CURVED I GIRDERS”, J. Structural Engineering, ASCE, 115(9), pp. 2145-2165, (1989).

[8] Heins, C. P. and Jin, J. O.: "LiVE LOAD DISTRIBUTION ON BRACED CURVED IGIRDERS”, J. Structural Engineering, ASCE, 110(3), pp. 523-530, (1984).

[9] Hirasawa, H., Hayashikawa, T. and Sato K.: "LOADING TESTS AND ANALYSIS OF CURVED TWO-GIRDER BRIDGES WITH LATERAL BRACINGS", The Eighth East Asia-Pacific Conference on Structural Engineering and Construction, Nanyang Technological University, Singapore, Paper no. 1135, (2001).

[10] El-Mezaini, N., Mahmoud, Z., and Sennah, K.: "COMPOSITE CONCRETE-STEEL I-GIRDER BRIDGE EVALUATION USING FINITE-ELEMENT ANALYSIS APPROACH”, International Conference on Structural \& Geotechnical Engineering and Construction Technology IC-SGECT'04, Mansoura, Egypt, Paper no. 128, (2004).

[11] Abdo, M. A.-B.: "EFfect OF Bottom LAteral Bracings ON The Behaviour Of Composite Steel-Concrete Bridges Curved In Plan”, J. Engineering Sciences, Faculty of Engineering, University of Assiut, 34(5), (2006).

[12] Huang, D.Z., Wang, T.L., and Shahawy, M.: "DYNAMIC BEHAVIOR OF Horizontally Curved I-GIRDER Bridges", J. Computers \& Structures, Vol. 57, No. 4, pp. 703-714, (1995).

[13] American Association for State Highway and Transportation Officials, (AASHTO): "GUIDE SPECIFICATION FOR HORIZONTALLY CURVED HIGHWAY BRIDGES”, Washington, D.C., (1996).

[14] MARC Analysis Research Corporation, Volumes; A, B, and C, Version 2001, (2001).

[15] MARC Analysis Research Corporation, Mentat User's Guide, Version 2001, (2001).

[16] EGYPTIAN CODE OF PRACTICE FOR STEEL CONSTRUCTION AND BRIDGES (ECP), Code No. (205), 255 pp., (2001). 


\section{دراسة بارامترية لتأثير الأحجبة وأنظمة السند العرضية على الإهتزاز الحر للكبارى من الصلب والمنحنية فى المسقط الأفقى}

إن تزويد الكباري بالأحجبة (Cross frames) أو أنظمة السند العرضية (Lateral bracing) systems)

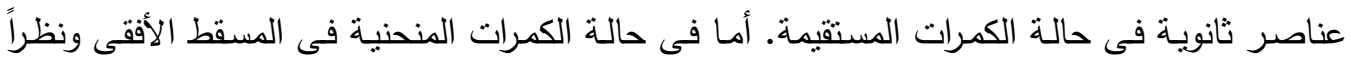

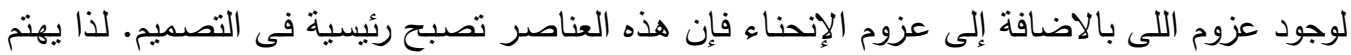

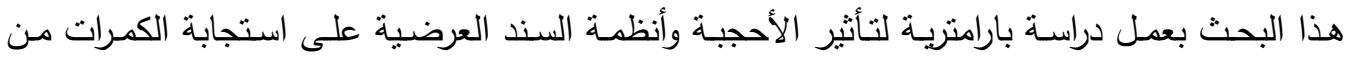

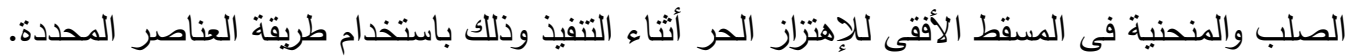
وقد تم تمثيل كلاً من الجذع والثفتين لكل كمرة بعناصر قتشرية سميكة (Thick shell elements). أما عناصر الأحجبة وأنظمة السند العرضية فتم تمثيلها بعناصر كمرية. وقد وجد من النتائج أن زيادة الكزازة لعناصر الأحجبة لها نأثير ضئيل على التئل التردد الطيبعي

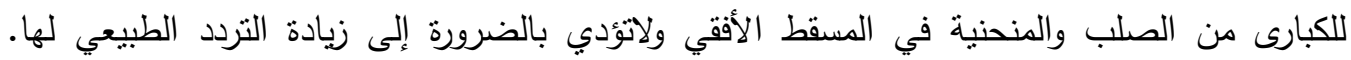
ويوصى بألتزيد نسبة النحافة لعناصر الأحجبة عن 140 لأن هذه النسبة تعطي أكبر تردد الطبيعي لكل درجات الإنحناء. كذلك يوصى بأن تكون العسافة بين الأحجبة فى حدود 3 إلى 5 مثر فى حلى حالة الكمرات

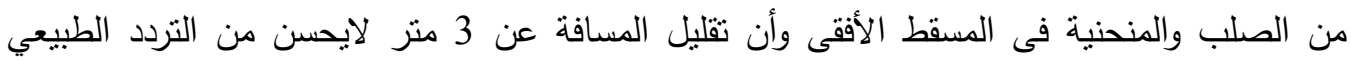

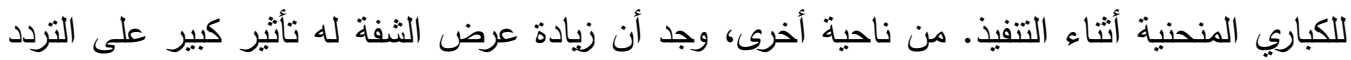

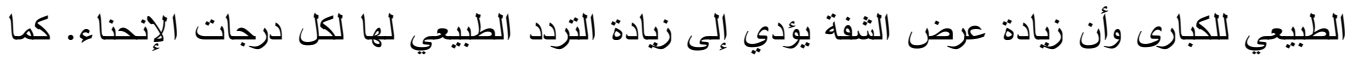

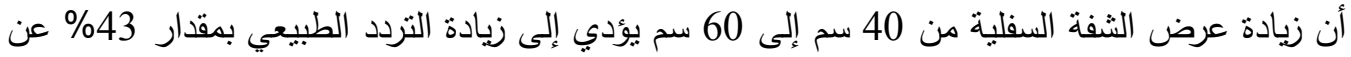
القطاع الأصلي. كما وجد أن زيادة عدد الكمرات أو المسافة بين الكمرات له نأثير ضئئيل على الإهنتزاز

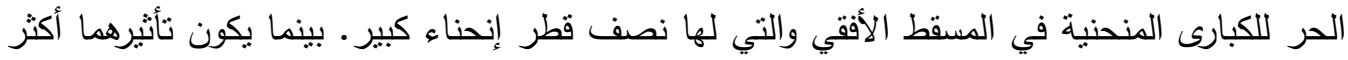
وضوهاً في الكمرات التي لها نصف قطر إنحناء صغير . وكلما زاد عدد الكمرات أو الماء المسافة بين الكمرات فإن التردد الطبيعي الأساسي للكمرات يزيد زيادة بسيطة وكذللك التزددات الأعلى درجة.

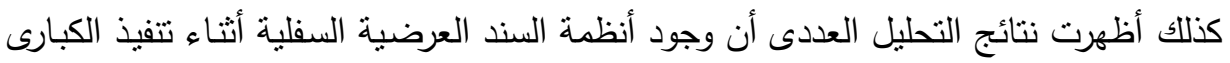

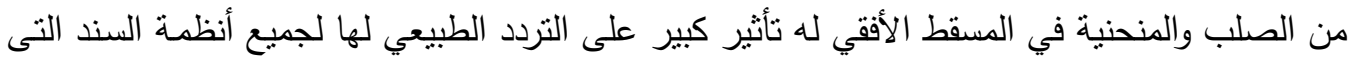

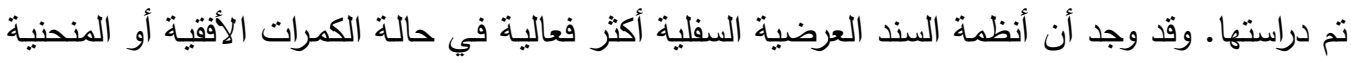

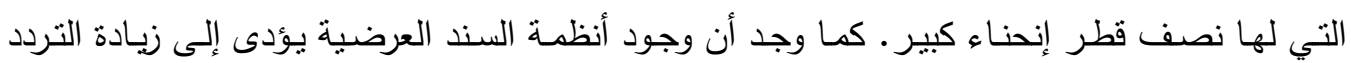

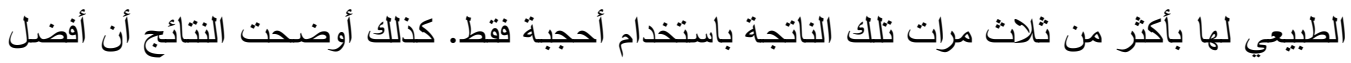

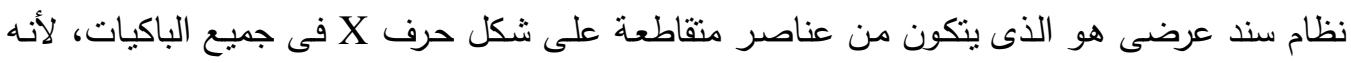
يعطى أكبر زيادة فى التردد الطبيعي للكبارى المنحنية. هذا وبالرغم من أن نمط السند الذى ينكون من النيات 
عناصر مثقاطعة على شكل حرف X ولكن فى البانوهات الأخيرة (End panels) فقط، يعطى أقل

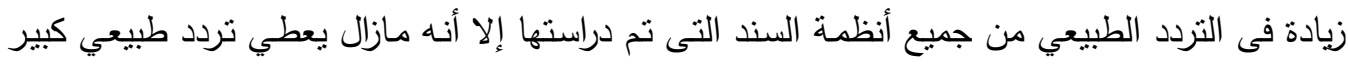
(أكثر من ضعف تلك الناتجة باستخدام أحجبة فقط). لذا فإن استخدام أنظمة السند العرضية السفلية لتقوية الكبارى بأي نمط من الأنماط التي تم دراستها مفيد جداً لتحسين السلوك الديناميكي لقطاعات التهات الكبارى الجديدة أثناء التتفيذ. 